\title{
The elusive cyber beasts: How to identify the communication of pro-Russian hybrid trolls in Latvia's internet news sites?
}

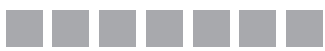

Anda Rožukalne

Klāvs Sedlenieks

RIGA STRADINS UNIVERSITY, LATVIA

DOI: 10.19195/1899-5101.10.1(18).6

\begin{abstract}
The research described here was performed on the background of the geopolitical fluctuations in Eastern Europe and the annexation of Crimea by Russia. These events caused fear of pro-Russian propaganda particularly in the so-called Internet hybrid-trolls, i.e., commentators who are on the payroll of Russian state agencies who disrupt internet discussion boards with massive pro-Russian information and opinions. This paper describes methodology of identifying possible hybrid-trolls, data gathering from the biggest Latvian online news sites (delfi.lv, apollo.lv, tvnet.lv) that provide information in Latvian and Russian language, and analysis of the data by means of quantitative analysis as well as qualitative, that included content analysis and a case study. The analysis shows that the presence of pro-Russian hybrid trolls is inconclusive. However, following the outlined methodology some cases were recorded. Quantitative as well as qualitative analyses demonstrate that the overall presence and exposure of the alleged trolls in the given period was insignificant and the influence of trolls on public opinion highly questionable.
\end{abstract}

KEYWORDS: Internet trolls, hybrid trolling, Internet users' comments, news sites, Latvia.

\section{INTRODUCTION}

The aim of this research is to identify particular kinds of internet trolls, that are or can be used as purposeful tactical weapons of hybrid warfare and more specifically - by pro-Russian forces. The background information suggests that Russian special forces maintain offices ("troll-farms" or "troll-factories") from which paid workers post information online with the purpose of distracting populations of Western countries (including Latvia) and to further Russian ideological claims. ${ }^{1}$ Therefore,

1 See for instance the story about an ex-troll who wins a court case against a former employer for not being paid that circulated the world media http://www.usnews.com/news/world/articles/ 2015/08/17/ex-kremlin-internet-troll-wins-suit-against-ex-employer. 
our task was to identify possible pro-Russian Internet trolls, to describe their spread, behavior, and possible impact.

The following is a detailed report of searching for the possible activity of paid pro-Russian Internet trolls in the five largest news sites that offer information in Latvian (delfi.lv, tvnet.lv, apollo.tvnet.lv) and Russian language (rus.delfi.lv, rus. tvnet.lv).

\section{INTERNET TROLLS, TROLLING AND HYBRID-TROLLS}

A troll is a native species of the Web, i.e., it has been there since the beginning of Internet communications. Although the idea and indeed the etymology of the term has morphed over time, the traditional understanding of an internet troll is associated with various kinds of rude, abusive and irritating behavior (Binns, 2012). According to Buckels et al. online trolling can be defined as "the practice of behaving in a deceptive, destructive, or disruptive manner in a social setting on the Internet with no apparent instrumental purpose" (2014, p. 97).

While trying to identify the Internet trolls and analyze their communication, scholars point out that the practice of the Internet trolls is characterized by a willingness to evoke a conflict, to create ad hominem attacks towards other participants, by provoking and manipulating (Donath, 1999; Dahlberg, 2001) with other discussion members. The communication of trolls is also linked with a specific Internet humor and public shaming (Stryker, 2011; Phillips, 2015). Joseph Reagle (2016) reminds that the term "troll" has possibly originated from another Internet term "fishing" or "trolling for newbies". He also believes that the popular saying "Don't feed the trolls" suggests ignoring activities created by "flame bait" (Reagle, 2016, p. 699).

The term "Internet trolling" has been slowly replacing the term "hating", becoming more popular than the previously used "flaming" (McCosker, 2014). Elizabeth Ellcessor (2016) offers to perceive trolling as an amplification of larger cultural forces. Trolling to a significant degree characterizes anonymous Internet communication and determines online culture; trolls on the Internet do not mean just a different way of communication, they are "relational phenomena" (Ellcessor, 2016). The content created by trolls has been also considered in a context of "participatory culture" (Jenkins, 2006) and "digital activism" (McCosker, 2014) formed due to the Internet.

The status of Internet trolls is characterized as an action of single players; more likely trolls are outsiders (Nissenbaum \& Shifman, 2015). Stephan Weichert stresses out that trolling has changed both journalism and media content, thus editors are forced to come up with a solution how to professionally deal with the constant confrontation with trolls, haters, dialogic diarrhoea of conspiracy theory followers and political extremists (Weichert, 2016). 
Hostile or conflict-oriented communication is not always trolling (Hwang \& Xu, 2014), it can be considered to be a "productive element of social media spaces" (McCosker, 2014). Antony McCosker (2014) uses the concept of the "agonistic pluralism" by Chantal Mouffe (2000) in order to remind that in a democratic discussion all significant ideas are being doubted, conflicts are inevitable, but they can be turned into a productive platform that gives freedom to all passions and shows the interaction of the opposite sides.

One of the characteristics of trolling is the ability "to hijack a discussion through harassment or inflammatory content, because the troll 'wins' when discussions descend into virtual shouting matches" (MacKinnon \& Zuckerman, 2012, p. 18). Various communication studies of comments and blogs show that Internet discussions are far from an ideal democratic debate (Powers, 2015). While analyzing the potential of the "networked public sphere" (Benkler, 2006, p. 212), it has to be admitted that it is characterized by breaking the ethics rules (Isin \& Nielsen, 2008), hate speech, attacks on differently thinking users, sexism, and stereotyping (Robertson, 2014).

This paper, however, analyses a new kind of trolling: a consciously planned and paid communication, the aim of which is to divert attention and create an impression that certain ideas and beliefs dominate public opinion and which is achieved by using trolling techniques such as pushing topics, attacking, discrediting public figures and officials or other communication participants.

The context of the study described here contains changes in the geopolitical situation in the world and the new phenomenon of hybrid-warfare that is often analyzed in a context of modern war strategies. While analyzing international terrorism and new international communication techniques, a great emphasis is put on the communication in a virtual environment, offering Internet users a specific content, persuading the audience pro or con certain ideas, politicians, and countries.

In order to separate ordinary Internet trolls from paid ones, we call the latter hybrid-trolls. The term is derived from "hybrid war" and is often used alongside the term "information warfare" (also "information war") in order to describe modern hostilities where conventional battles are combined with influencing the population through information in certain areas (McCuen, 2008). Information warfare or hybrid war is attributed to processes when real warfare does not take place, but countries and territories are being "conquered". To describe communication which helps to affect the indigenous population by changing views, evaluation, and behavior, the term "psychological warfare" is used (Nissen, 2015). Andrei points out that good propaganda can replace warfare because "the principles of an information war remain unchanged: you need to de-humanize the enemy" (Aliaksandrau, 2014, p. 57). As it was believed that hybrid trolls should be a relatively cheap and still very effective tactical weapon, news of "troll-factories" spread throughout world news outlets. 
Soon after the Maidan events in Kiev and the annexation of Crimea in 2013 and 2014, publications on the paid "troll army" organized by the Russian government appeared (Sindelar, 2014; Bugorkova, 2015). The task of paid Internet trolls according to these sources was to offer the message suited to Russian government policy in the virtual environment, offering an interpretation of the current events, facts, and personalities, while creating an impression that the participants of the communication belong to the community of readers and represent usual Internet users. The aim of Internet trolls is to change the public mood in favor of Russia's official policy by discrediting opposition politicians, as well as offering facts and interpretations that support the Russian government's official position on Internet discussion sites.

Most of the information on Russian hybrid-trolls comes from articles of investigative journalists (Hermant, 2015; Walker, 2015). However, actual academic research of the phenomenon so far remained thin on the ground.

\section{RESEARCH DESIGN AND METHODOLOGY}

From the researchers' point of view one of the biggest challenges is to identify paid hybrid-trolls, knowing that they operate in a diverse communication environment where anonymous participants can join the discussion and leave at any time while offering any content, and adapting any behavior or identity. This study offers both criteria for detection of hybrid-trolls as well as analysis of their communication in the comment sections of online news sites.

We divided the study in the quantitative part, analyzing the corpus of all posted comments, and the qualitative part which looked at the detected trolls' behavior and interaction with other users. The content analysis was conducted by analyzing 207,707 comments posted from 20,006 IP addresses during one week in 2014 (29.07.2014-05.08.2014). The comments were obtained in cooperation with the administration of the news sites that prepared and sent us the raw data of all comments that were posted (regardless of whether they were actually displayed later on the site).

In the quantitative part of the study we were trying to answer the following questions:

1) Are there any identifiable pro-Russian paid Internet trolls? A rigorous approach requires that a skeptical stance should be taken rather than confirming opinions expressed in the media and rumored among the general public.

2) If "yes", what is their relative quantity? This question is important to estimate the possible impact of the trolling.

3) Which news topics attract trolls? This may be used as a proxy to identify the political agenda of the possible trolls' employers.

4) Is there any difference between the questions above in Russian language and Latvian language parts of the news sites? 
We made several background assumptions about the trolls prior to the research based on the available information about what kind of behavior the paid pro-Russian troll should conform to:

1) The troll should post many comments;

2) The troll should be consistently one-sided;

3) The troll should re-post Russian mass media messages (to produce a large quantity of comments, the most effective way of spreading information is to re-post fragments of pro-Kremlin media outlets or links to them);

4) The troll should not engage in conversations or engage in conversations only occasionally (Engaging in conversations is time-consuming although psychologically could be the most effective.);

5) The troll should not comment on random and mundane topics that are totally unrelated to the ideological task and/or on comments that are not ideological.

The raw data that was used for the quantitative analysis contains the following information: publishing date of the comment; the title of the article; text of the comment; unique IP address identifier ${ }^{2}$ which the comment was posted from; comment author's nickname.

Therefore, there are two items that can identify the author - the IP identifier and the nickname. However, none of them is sufficiently reliable. Several authors can post from one IP address. Alternatively one author can post from many different IP addresses. Moreover, nothing binds the user to employ just one nickname. To complicate matters, a single user can change both - the IP address and the nickname. Therefore, it is impossible to identify an individual author mechanically, relying only on these parameters.

Based on the background assumptions above, we set the following criteria that a troll should conform to in order to be identified as such (further referred as Criteria for Trolls):

1) It must have posted more than 15 posts during the investigation period;

2) It must be consistently pro-Russian;

3) It must either post links to pro-Russian web-pages or large chunks of copypasted information from such pages;

4) Generally, it must not engage in conversations with other users;

5) It must not comment on mundane and non-political topics unless the comments are political and pro-Russian;

6) It must be repetitive, reposting the same message multiple times rather than craft purpose-made comments that are content-specific;

2 Prior to sending the comments to us the portal administration anonymised the comments by transforming IP addresses into unique IP identifiers which allowed identification of separate posting sources, but did not allow further identification of it. 
7) For most of the research, the authors/comments that conform to the criteria above but that are anti-Russian will be ignored. ${ }^{3}$

The following steps were taken in order to obtain a list of possible trolls:

1. Sorting by IP.

2. Manual scanning. The data was manually scanned and all the messages posted from one IP address that conformed to the Criteria for Trolls were marked as possible trolls.

3. Filtering the cases. Additional filtering was applied to remove those messages or IP addresses that displayed inconsistent behavior with the criteria above.

Thus we firstly looked for messages that were posted from one IP identifier and that displayed the supposed behavior of hybrid trolls. However, it could have been the case that trolls change their IP address. Therefore we also checked whether we could identify similar pro-Russian posts coming from different addresses.

In order to estimate the capacity of impact of paid pro-Russian trolls, the percentage of the trolling messages vis-à-vis other messages was calculated. Secondly, a simple content analysis of the articles which have attracted troll activity was performed, marking the overall topic of the article.

Due to the particular character of Internet communication and the character of the available data, there are certain limitations that must be kept in mind. First, the identification of possible trolls includes a great deal of subjectivity. We were doing our best to evaluate the plausibility that the author is or is not a paid troll, but there is still a possibility that not all trolls are identified correctly or that ordinary commentators are falsely identified as paid trolls. Second, the whole context of Internet communication was not properly investigated. We did observe numerous cases of anti-Russian posts that clearly expressed troll-like features, but did not analyze them due to lack of time and other resources. Third, the original dataset for this research comes from a short period of time. Therefore, it is impossible to make any kind of quantitative conclusions about the overall change of mood because that would require a longitudinal method.

\section{RESEARCH RESULTS}

The corpus of analyzed comments consists of 207,707 comments that were posted from 20,006 IP addresses. We found 48 unique IP identifiers that were demonstrating commenting activity corresponding to the Criteria for Trolls. The 48 unique IP addresses produced in total 2,967 comments out of which 1,721 comments were posted in Latvian and 1,242 comments - in Russian news portals.

3 Even a brief glance at the comment environment shows that there is a large quantity of such comments. A proper analysis of the trolling environment should be analysing all such "worriers of cyberspace". However, due to the limited time and other resources and because the primary task of this research is to identify pro-Russian trolls and their potential, the anti-Russian trolls were ignored for most of the research. 


\section{Results of the quantitative part}

Table 1. General numbers characterizing the corpus

\begin{tabular}{|l|c|}
\cline { 2 - 2 } \multicolumn{1}{c|}{} & NUMBER OF ITEMS \\
\hline Number of posted comments (all comments from all IP identifiers): & 207707 \\
\hline Number of unique IP identifiers & 20006 \\
\hline Number of possible trolling IP identifiers & 48 \\
\hline Number of comments from the trolling IP identifiers & 2967 \\
\hline Number of comments from the trolling IP identifiers in Latvian portals & 1721 \\
\hline Number of comments from the trolling IP identifiers in Russian portals & 1242 \\
\hline Number of other (non-trolling) comments & 204740 \\
\hline Percentage of trolling comments from all corpus of comments & 1.45 \\
\hline
\end{tabular}

Total percentage of trolling comments from all the corpus of the comments constitutes $1.45 \%$. This number, however, relates to all comments that were posted during the studied period on three portals, including articles about sports, cooking and other topics that were not related to anything that might trigger the interest of the hired Internet trolls. Therefore, it was important to find out what was the proportion and intensity of the trolling comments in relation to non-trolling comments in those articles where the identified trolls have been active (see Table 2).

Table 2. Total numbers of trolling and non-trolling messages posted in relation to the articles that attracted at least one troll comment

\begin{tabular}{|c|c|}
\hline NUMBERS RELATED TO TROLLED ARTICLES ONLY & NUMBER OF ITEMS \\
\hline \multicolumn{2}{|l|}{ ALL LANGUAGES } \\
\hline Number of trolling comments & 2967 \\
\hline Number of non-troll comments & 79808 \\
\hline Percentage of trolling comments (only trolled articles) & 3.72 \\
\hline \multicolumn{2}{|l|}{ RUSSIAN LANGUAGE PORTALS } \\
\hline Number of trolling comments in Russian portals & 1243 \\
\hline Number of non-troll comments in Russian portals & 31149 \\
\hline Percentage of trolling comments in Russian portals (only trolled articles) & 3.99 \\
\hline \multicolumn{2}{|l|}{ LATVIAN LANGUAGE PORTALS } \\
\hline Number of trolling comments in Latvian portals & 1721 \\
\hline Number of non-troll comments in Latvian portals & 48499 \\
\hline Percentage of trolling comments in Latvian portals (only trolled articles) & 3.55 \\
\hline
\end{tabular}


Table 2 shows that the percentage of trolling messages in articles that attracted the attention of trolls is significantly higher but is still below 4\%. Portals in Russian have experienced slightly higher troll activity, reaching almost $4 \%$, but in general, the difference is insignificant (Figure 1).

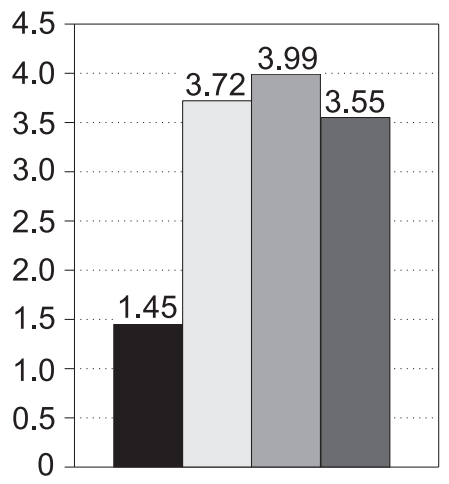
Percentage of trolling comments from all corpus of comments Percentage of trolling comments (only trolled articles)
Percentage of trolling comments in Russian portals (only trolled articles)
Percentage of trolling comments in Latvian portals (only trolled articles)

Figure 1. Comparison of percentage of trolling messages from the total number of messages $(100 \%=$ total number of comments posted during the period)

The above information demonstrates that although there are some variations across languages, the total percentage of messages posted by the hired trolls is minor. The activity of the hired trolls across various topics was not uniform as illustrated in Figure 2.

Almost $1 / 3$ of all troll comments were linked to events in Ukraine. A closelyrelated topic connected to shooting down the Malaysia Airlines flight MH17 over Eastern Ukraine also attracted a comparatively high proportion of trolling messages. If these two categories were combined into one, they would make $37 \%$ of all messages posted by suspected hired trolls.

The second largest section that attracted troll attention is related to Western sanctions against Russia and Russian countermeasures in a form of embargo for products from Western countries, including Latvia. This topic constitutes $27 \%$ of all comments.

The hypothesis that paid trolls are flooding the comments with identical messages that are posted from different IP addresses and that this could be used as criteria for identifying a hybrid troll was also tested. Overall there were 9,784 messages that were repeated at least once. Most were posted from the same IP addresses and therefore already scrutinized when the corpus was analyzed from the IP identifiers' point of view. However, we found that 924 messages or $0.4 \%$ of all comments were repeated from more than one IP address. Only $14 \%$ of these comments expressed a point of view that supports Russia's politics or the content was pro-Russian, while $40 \%$ of the comments criticized Russia's politics or the com- 


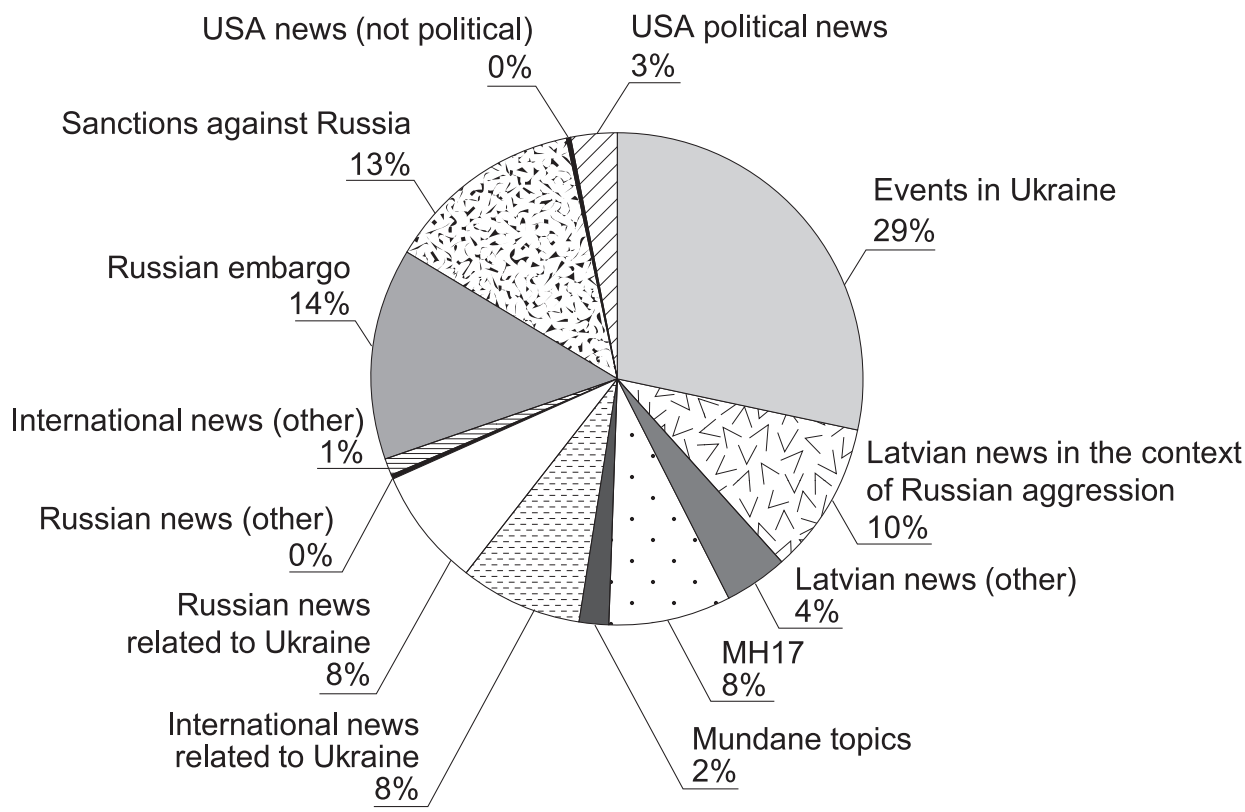

Figure 2. The spread of trolling comments across articles of various comments. Categories reflect topics of the articles $(100 \%=$ a total number of trolling comments posted in the period)

ments were anti-Russian, but the context led us to think that even these were most probably not posted by paid trolls (see Figure 3).

Answers to research questions of the quantitative part:

1) Are there any identifiable pro-Russian paid internet trolls?

It is difficult to give a convincingly positive answer to this question. However, following the methodological principles, 48 different IP addresses were identified that produced messages that provide grounds for assuming that there might be pro-Russian paid Internet trolls operating in Latvian news portals.

2) What is the relative quantity of paid trolls?

The total number of individual IP identifiers that could be identified as paid trolls is tiny in comparison to the overall number of unique IP identifiers (48 out of 20,006 , which is $0.2 \%$ ). However, the proportion of messages that these possible trolls produce in relation to articles in which they operate can go up to $4 \%$ of all posted messages (this number is on average, a few individual articles may contain a significantly larger proportion).

3) Which topics of news are attracting trolls?

The suspected trolls were operating almost exclusively in articles that were related to events in Ukraine either directly or indirectly.

4) Is there any difference in the questions above in Russian and Latvian portals? 


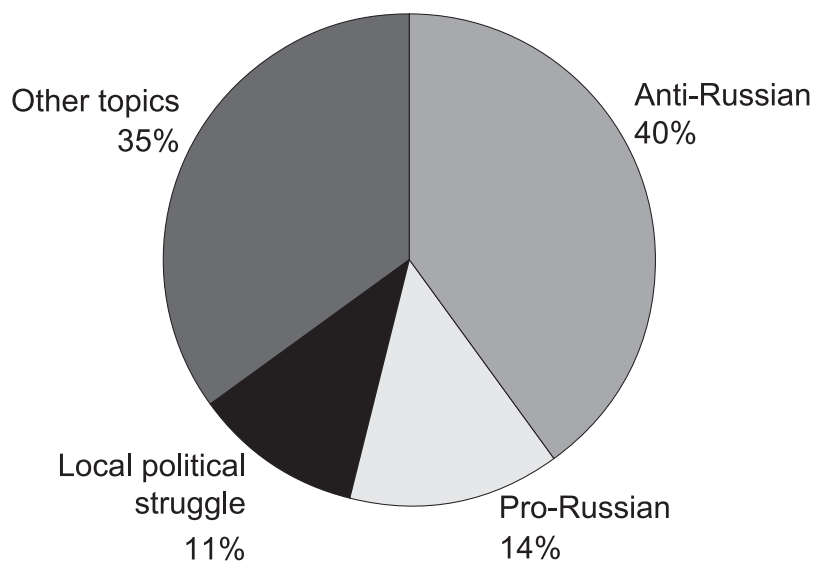

Figure 3. Attitude towards Russia in comments that were posted multiple times from more than one IP address. Category "other topics" include mostly commercially oriented spam, usually of a sexual character

Russian portals display slightly higher activity of the possible pro-Russian trolls but the difference is not large.

The nature of the analyzed quantitative data does not allow documenting the direct influence of trolling messages in other users' opinion. The qualitative part of the research demonstrates a more nuanced picture, showing that the Latvianspeaking environment is less subject to influence than Russian, but in both cases pro-Russian trolls get little exposure and their capability to influence public opinion is limited.

\section{Results of the case analysis of the most active "trolls"}

During the first phase of the research we collected a large quantity of data, containing user comments from Latvian news sites. We now use the case study approach with the aim to get beyond the initial impressions and describe the actual dynamics of the posts.

By means of the case study we looked for answers to the following research questions:

1) What are the communication models of hybrid pro-Russian trolls?

2) What is the content provided by hybrid pro-Russian trolls?

3) How do hybrid pro-Russian trolls interact with other news site commentators?

4) How do technical means (software) and human activities (editors of the comments sections) impact the content provided by hybrid pro-Russian trolls?

The design of the case study is based on quantitative and qualitative categories that include the troll's nickname, the number of comments, and the number of 
articles, news sites chosen for posting comments, forms and topics of the content of posted comments. In order to investigate other users' interaction models, behavior and reaction to the comments posted by trolls we used the comments that we identified as ones belonging to the possible hybrid trolls in the quantitative part of the study and looked at them in the actual environment of the comments sections of the news sites.

It must be kept in mind that a large part of the comments written by the most active trolls are deleted by the administrators of the news portals. Thus they were available for us to study, but were not visible to other readers. In order to understand the policy of the site administration towards deleting comments we interviewed the editors of the respective sites.

For the case study we chose the seven most active (users that posted more than one hundred comments to more than 20 news articles during one week) hybrid pro-Russian trolls. Overall the behavior follows a similar path, so out of those seven only the three most typical are illustrated below.

Case analysis no 1.

\begin{tabular}{|c|c|}
\hline Nick name: & ново-россия (new Russia) \\
\hline IP identifiers & $472386 ; 642096 ; 727365 ; 773718 ; 775430$ \\
\hline $\begin{array}{l}\text { Number of comments } \\
\text { and articles }\end{array}$ & 49 articles, 156 comments \\
\hline News sites & $\begin{array}{l}\text { Commenting only on Delfi.lv and rus.delfi.lv, covers both Latvian } \\
\text { language and Russian language news. }\end{array}$ \\
\hline Typical behavior & $\begin{array}{l}\text { Actively republishes fragments from Russian media. Criticizes opinions } \\
\text { about Russia-related topics in Latvian politics by adding ad hominem } \\
\text { expressions. } \\
\text { Combines personal expressions and the information from Russian official } \\
\text { news agencies and the Internet media sites, for example, www.novorosin- } \\
\text { form.org and www.bragazeta.ru. } \\
\text { Disputes the content of news stories by defending the Russian version of } \\
\text { the events. }\end{array}$ \\
\hline Typical content & $\begin{array}{l}\text { Events in Ukraine. Investigation of the crash of "Malaysia Airlines" flight } \\
\text { MH17. Opinions of Latvian politicians related with the events in } \\
\text { Ukraine. EU sanctions to Russia. }\end{array}$ \\
\hline Interaction models & Does not interact with other users. \\
\hline
\end{tabular}

Conclusions on "ново-россия":

- The commenter reacts precisely to the content of a news story by choosing particular topics for comments.

- The main aim of commenting - to provide alternative information about the events and cultivate pro-Russian interpretation of the particular events. 
- All of the analyzed comments have been deleted by the administrators of the news sites. Part of the comments can be interpreted as the promotion of national and ethnic hatred.

- Reposting of information from Russian media outlets helps to pretend that the provided information is truthful and reliable.

Case analysis no 2.

\begin{tabular}{|l|l|}
\hline Nick name: & jurmala and many others (e.g. kurmitis, vovan, kaiminjsh etc.) \\
\hline IP identifier & 513506 \\
\hline $\begin{array}{l}\text { Number of comments } \\
\text { and articles }\end{array}$ & 66 news stories, 323 comments \\
\hline News sites & Commenting only on Apollo.lv in Latvian language \\
\hline Typical behavior & $\begin{array}{l}\text { Commenter repeats the same comments several times. } \\
\text { The form of published comments of the troll recall angry slogans. } \\
\text { By adding the address as a nickname (for example: to the USA, to } \\
\text { Embassy of the U.S., to Rinkēvičs (minister of foreign affairs of Latvia)) } \\
\text { the commentator demonstrated that he/she wants to speak to a particular } \\
\text { institution or individual. } \\
\text { All comments by "jurmala" are related to the topics of news stories. } \\
\text { Sometimes the intonation of "jurmala" comments became hysterical by } \\
\text { the form and content. } \\
\text { The author of the comments also expresses rude and offensive comments } \\
\text { that may contain xenophobic statements especially about (but not limited } \\
\text { to) Jews. }\end{array}$ \\
\hline Typical content & $\begin{array}{l}\text { "jurmala" comments mostly about the foreign policy of Latvia, foreign } \\
\text { news from the U.S. sanctions, news on events in Ukraine. }\end{array}$ \\
\hline Interaction models & $\begin{array}{l}\text { Commenter does not interact with other users in any of the possible } \\
\text { forms. }\end{array}$ \\
\hline
\end{tabular}

Conclusions on "jurmala":

- "jurmala" behaves extremely aggressively and actively by adding several comments to the same article;

- He/she tries to dominate within the comments environment of the news site by publishing large numbers of comments;

- "jurmala" represents only a few ideas and tries to increase the visibility of particular ideas on Russia's interpretation of actual events;

- "jurmala" constantly addresses comments to particular individuals (state authorities) and institutions;

- The comments are filled with hatred towards the United States as a country, and to the politicians or organizations of Latvia, EU or US;

- Stable demonstration of irrational hatred and xenophobic statements of "jurmala" may be the reason for the deletion of the all comments written by this commenter. 
Case analysis no 3.

\begin{tabular}{|l|l|}
\hline Nick name: & подполковник гоцман (lieutenant-colonel Gocman) \\
\hline IP identifier & 771323 \\
\hline $\begin{array}{l}\text { Number of comments } \\
\text { and articles }\end{array}$ & 116 comments, 15 articles \\
\hline Portals & Commenting only in rus.delfi.lv covers only Russian news stories \\
\hline Typical behavior & $\begin{array}{l}\text { In the comments the "lieutenant-colonel Gocman" criticizes the United } \\
\text { States and other countries except Russia. By commenting about flight } \\
\text { MH17, he/she protects the pro-Russian version of events. } \\
\text { This commenter provides rational criticism towards conclusions of } \\
\text { experts. } \\
\text { "lieutenant-colonel Gocman" responds to the particular content of news } \\
\text { by using of fragments from Russias media. } \\
\text { He/she raised a discussion on manipulation with information within the } \\
\text { comments environment of the news site. }\end{array}$ \\
\hline $\begin{array}{l}\text { Characteristics of } \\
\text { provided content }\end{array}$ & Flight MH17 catastrophe \\
\hline $\begin{array}{l}\text { Interactivity models } \\
\text { Foes not participate in the conversation. }\end{array}$ \\
\hline
\end{tabular}

Conclusions on “подполковник гоцман”:

- The main aim of this commenter is to change the discourse around news about the catastrophe of flight MH17;

- Many of his/her comments are hidden by the technical tools of the web page because of the negative evaluation from other users;

- The content and intonation of his/her comments are polite and rational.

Answers to the research questions of the qualitative part:

1) What are the communication models of hybrid pro-Russian trolls?

The analysis of communication models of possible Internet trolls shows that the analyzed commentators ensure one-sided communication; they try to dominate in the comment sections of news sites by the number of posted comments, and the communication form and content, but hybrid-trolls do not join in discussions with other commentators as predicted during the development of the Criteria for Trolls. A large part of the comments of analyzed hybrid - trolls are hateful, xenophobic, attacking, therefore they are deleted by the administrators of news sites. Rapid commenting in a short period of time (submitting several comments every few seconds) is forbidden on news sites. ${ }^{4}$

The most important goals of the Internet trolling activities within the environment of Latvian news sites appear to be the following:

4 Data from interviews with the editors of news sites Tvnet and Apollo. 
- To offer massive amounts of information which supports Russian propaganda messages;

- To change the behavior of other commenters and the overall content of the comment section of news sites;

- To change other readers' opinions about the issue;

- To maintain an atmosphere of alarm and distrust;

- To create fear about the further development of the event ("Russia is the most powerful state in the world", "Russia is going to take revenge", "EU sanctions are useful only to the U.S.", "other EU countries benefit on the suffering of the inhabitants of Latvia", "Latvians are hurting themselves by joining EU sanctions";

- To create doubt over whether the information offered by the news site is true and diverse.

2) What is the content provided by hybrid pro-Russian trolls?

By adding referenced excerpts from Russian news media articles, the trolls are trying to make an impression, that the information provided by them is true and reliable. It can provide useful lessons to readers and change their perception of the events.

3) How do hybrid pro-Russian trolls interact with other commenters?

The majority of pro-Russian trolls show robot-like behavior by posting comments, but rarely interacting with other users. The comments of hybrid-trolls express opinions about the news content, but they do not react to the comments of other commenters. The participation in discussions between commenters is time consuming, therefore the behavior of pro-Russian trolls confirms the assumption (and the evidence of former paid trolls) that paid trolls have to fill the online environment with particular content. This reciprocity (Kiousis, 2002; Sohn \& Choi, 2014) part that is essential for the interactivity partly appeared and has not been reached during the communication process.

4) How do technical means (software) and human activities (editors of the comments sections) impact the content provided by hybrid pro-Russian trolls?

The absolute majority $(60 \%-70 \%)$ of the particular comments were deleted by the administration of the portals. Research data confirms that the technical tools and editors' strategies to avoid violence and hate inciting content are effective for the limitation of Internet trolling activities. The main strategy of the administration is related to the laws that regulate media content (violent content and incitement of ethnic hatred is prohibited) and the rules for commenting set up by the management of portals. At the tactical level, aggressive commenters are banned; many similar texts that are posted during a short period of time are deleted; a part of rude and insulting comments are deleted by automated tools guided by keywords used in the particular comments.

Reaction of other users differs by the main language of the news site. In Latvian versions of the portals, the trolls' comments often are automatically hidden after 
they receive overwhelming negative feedback from other readers. ${ }^{5}$ In the Russian version of the sites audience members give almost the same number of positive or negative feedback to trolls' comments. It may be explained with the assumption that among users of Russian portals, there are more individuals who support opinion(s) expressed by the trolls. Some articles (in rus.tvnet.lv) have been commented on almost exclusively by trolls (for example, Торжества железной дороги могут омрачить санкиии (Celebration of the new railway project may be overshadowed by sanctions), a total of 29 comments of which 23 are troll comments). Nevertheless most trolls usually get attacked by other users in Russian news site rus.delfi.lv. The attackers usually engage in arguing with trolls, expose them as trolls, question authenticity of the popularity of particular troll comments or complain about the practice of the administrator to keep radical comments in the comment environment.

Thus, although the trolls might have somehow a greater influence on Russian readers, they nevertheless are quickly identified as trolls and attacked by other commentators in all sites.

\section{CONCLUSIONS AND DISCUSSION}

Reading of news is the most common activity of Internet users in Latvia - 56\% of inhabitants of Latvia read news provided by the largest news sites (TNS Latvia, 2013/2014). Internet media delfi.lv and tvnet.apollo.lv are the main sources of information for $21 \%$ of residents of Latvia. News site Delfi.lv attracts $66 \%$ of all Internet users in Latvia (845,633 unique users); tvnet.apollo.lv attracts $58 \%$ of the all Internet users in Latvia (822,687 unique users). Although social media communication is often associated with the influence of paid trolling activities, in this research we chose the comment sections of the largest news sites because international social media did not have a large audience at the time when the research on internet trolls was elaborated. Only $17.5 \%$ of internet users of Latvia visit Facebook on a daily basis, 11.2\% use YouTube, and 5.4\% use Twitter every day (LSM, 2012). The most popular social media is local social portal draugiem.lv that attracts $60 \%$ of internet users, mostly representatives of Latvian nationality. According to the SKDS study $(2013)^{6} 3 \%-4 \%$ of Internet users in Latvia write comments every day; $16 \%$ write comments about once a week, and $16 \%$ to $20 \%$ of Internet users regularly read comments written by other audience members.

5 If other users evaluate a comment more negatively (with -) than positively (with +) then the comment disappears under the headline "Hidden comment"; hidden comments are available by additional clicking in news site Apollo.tvnet.lv.

${ }^{6}$ Data from SKDS national survey (November 2013) that was carried out for the research procect of Riga Stradiňš University "Overcoming the crisis in Latvia: economic, social and communication aspects”, 2013-2015. 
The analysis of the audience data of delfi.lv, rus.delfi.lv, tvnet.lv, rus.tvnet.lv, apollo.lv (see Annex 1, table 3) shows that Latvian language portals attract a larger audience, but the average time spent per visitor differs by portal and by the language of the audience members. Users of rus.delfi.lv are more active than others, spending more time on the site (average time spent per visitor is $00: 48: 41$ ), they stay longer on the site (average time spent per visit is 00:12:49), but they visit the site less often (average visits per visitor - 3.8) than users of tvnet.lv (average visits per visitor - 4.15).

Although pro-Russian trolls comment on the most popular first-page news, the data confirms the assumption that the contact of each reader with trolls' comments is short and rare and therefore can hardly change other Internet users' existing opinion.

The case analysis confirms conclusions from the quantitative and qualitative analysis that the eventual influence of pro-Russian Internet trolling messages in the comments sections of Latvian news sites is limited by various circumstances.

Most Internet trolls write comments only on one site or a section of the site, some of the analyzed trolls comment on the same articles. It means that their messages do not reach all of the potential audience. Still, the proportion of their comments on the articles that the trolls have commented on (usually two or three) is insignificant.

The eventual cultivation effect of trolls' messages is weak because, first, the audience has access to different content and second, the activity of audience members helps to develop critical evaluation skills towards all content provided by internet commenters, including trolls.

Paid pro-Russian trolls operating in Latvia can influence specific groups of users if they confirm their existing opinions about Russia, United States, and EU policy, and significant socio-political events. A part of commenters do not agree with trolls when they praise Putin's politics, but support the criticism towards the EU and U.S. or Latvian authorities.

The stimulus-response model explains how a stimulus - a message — changes the cognition, attitude, affects and communicative action by an individual involved in the communication where this message has been circulated. This simple model is helpful for contemporary researchers to explain how the initial communicators and what kind of messages affect the actions of other participants (Cheung \& Thadani, 2012). Our analysis shows that the stimulus part is limited by a relatively small number of messages which is reduced due to actions of the administration. This is further minimized due to the negative reaction from other commentators. As a result the response part (or the effect of the message provided) becomes weaker.

Castells describes the network logic in social and media theory as a dynamic system model for understanding problems and processes in contemporary society (Castells, 1999). This includes not only such phenomena as convergence, interactiv- 
ity, de-hierarchization and de-centralization but also a completely new kind of logic of communication (Ruths \& Pfeffer, 2014) that is used to describe ways and sources of power in society (Castells, 2009).

Using this theoretical approach to interpret the communication of pro-Russian trolls, we can come to some conclusions on the instability of power of various communication actors. Specifically, the unique status of online community members and their behavior can create barriers for the influence of trolls even if they have more time and other resources to communicate.

Internet commentators belong to a more active part of the audience, therefore according to cultivation theory and theory of audience gratification and media use (McQuail, 2010) users are able to resist the influence of media content. Judging by the content of Internet news sites, most of the commenters stand by different opinions and dismiss the form of commenting employed by trolls, i.e., rudeness, hatred, aggressiveness, swear words. The activities of trolls do not change the dominating opinion about selected topics in the content created by other commentators.

Theoretical assumptions allow us to reach the conclusion that the amount of comments produced is not large enough to cause a change of opinion, especially taking into consideration that this is not nearly the only opinion out there. If trolls that have been identified as such by this analysis are indeed paid hybrid-trolls, they operate in a keen competition with other activists, readers, portal censors and anti-spam software. Moreover, their exposure to actual readers is small.

It is difficult to speculate on the basis of this analysis of what could be achieved if the activity of the trolls is increased. However, taking into consideration the conformity tendencies and the effects of public opinion observed elsewhere such influence is possible. Whether it is financially viable to achieve it by means of trolling is another issue.

\section{REFERENCES}

Aliaksandrau, A. (2014). Brave new war. The information war between Russia and Ukraine. Index on Censorship, 43 (4), pp. 56-60.

Benkler, Y. (2006). The Wealth of Networks: How Social Production Transforms Markets and Freedom. New Haven, CT: Yale University Press.

Binns, A. (2012). Don't feed the trolls! Journalism Practice, 6 (4), pp. 547-562.

Buckels, E.E., Trapnell, P.D., Paulhus, D.L. (2014). Trolls just want to have fun. Personality and Individual Differences. Retrieved August 11, 2016 from http://dx.doi.org/10.1016/ j.paid.2014.01.016.

Bugorkova, O. (2015, March 19). Ukraine conflict: Inside Russia's 'Kremlin troll army'. BBC. Retrieved July 16, 2016 from http://www.bbc.com/news/world-europe-31962644.

Castells, M. (1999). The Rise of the Network Society. The Information Age: Economy, Society, and Culture, vol. 1. New Yersey: Blackwell Publishing.

Castells, M. (2009). Communication Power. Oxford: Oxford University Press.

Cheung, C.M., Thadani, D.R. (2012). The impact of electronic word-of-mouth communication: A literature analysis and integrative model. Decision Support Systems, 54 (1), pp. 461-470. 
Dahlberg, L. (2001). The Internet and democratic discourse. Exploring the prospects of online deliberative forums extending the public sphere. Information, Communication \& Society, 4 (4), pp. 615-633. Retrieved August 14, 2016 from http://epphenicie.iweb.bsu. edu/5820550.pdf.

Donath, J.S. (1999). Identity and deception in the virtual community. In: Smith. M.A., Kollock, P. (eds.). Communities in Cyberspace. London, UK: Routledge, pp. 27-58.

Ellcessor, E. (2016). Cyborg hoaxes: Disability, deception, and critical studies of digital media. New Media \& Society, 18 (10), pp. 1-17. DOI: 10.1177/1461444816642754.

Hermant, N. (2015, August 13). Inside Russia's troll factory: Controlling debate and stifling dissent in internet forums and social media. ABC. Retrieved July 17, 2016 from http://www.abc.net.au/ news/2015-08-12/inside-russia's-troll-factory-internet-forums-social-media/6692318.

Hwang, T., Xu C. (2014). 'Lurk more': An interview with the Founders of ROFLCon Tim and Christina Xu. Journal of Visual Culture, 13 (3), pp. 376-387.

Isin, E.F., Nielsen, G.M. (2008). Acts of Citizenship. London, UK: Zed Books.

Jenkins, H. (2006). Convergence Culture: Where Old and New Media Collide. New York: New York University Press.

Kiousis, S. (2002). Interactivity: A concept explication. New Media \& Society, 14 (3), pp. 355-383.

LSM (2012). Pètījumā noskaidrots sociālo tìklu lietojums Latvijā [The study shows the use of social networks in Latvia]. Retrieved November 6, 2016 from http://www.lsm.lv/lv/raksts/latvija/zinas/ petiijuma-noskaidrots-socialo-tiiklu- lietojums-latvija.a27372/.

MacKinnon R., Zuckerman E. (2012). Don't feed the trolls. Index On Censorship, 41 (4), pp. 14-24.

McCosker, A. (2014). Trolling as provocation: YouTube's agonistic publics. Convergence: The International Journal of Research into New Media Technologies, 20 (2), pp. 201-217.

McCuen, J.J. (2008, March-April). Hybrid wars. Military Review, p. 108.

McQuail, D. (2010). McQuails' Mass Communication Theory, 6th ed. London: SAGE Publications.

Mouffe, C. (2000). For an agonistic model of democracy. In: O'Sullivan, N. (ed.). Political Theory in Transition. London, UK: Routledge, pp. 113-132.

Nissen, T.E. (2015). The Weaponization of Social Media - Characteristics of Contemporary Conflicts. Copenhagen: Royal Danish Defence College.

Nissenbaum, A., Shifman, L. (2015). Internet memes as contested cultural capital: The case of 4chan's /b/ board. New Media \& Society, 17 (10), pp. 1-19.

Phillips, W. (2015). This is why we can't have nice things: Mapping the Relationship between Online Trolling and Mainstream Culture. Cambridge, MA: MIT Press.

Powers, D. (2015). First! Cultural circulation in the age of recursivity. New Media \& Society, 17 (8), pp. 1-16.

Reagle, J. (2016). The obligation to know: From FAQ to feminism. New Media \& Society, 18 (5), pp. 691-707.

Robertson, V. (2014). Of ponies and men: My Little Pony: Friendship is Magic and the Brony fandom. International Journal of Cultural Studies, 17 (1), pp. 21-37.

Ruths, D., Pfeffer, J. (2014). Social media for large studies of behaviour. Science, 346 (6213), pp. 1063 1064.

Sindelar, D. (2014, August 12). The Kremlin's trolls army. The Atlantic. Retrieved July 16, 2016 from http://www.theatlantic.com/international/archive/2014/08/the-kremlins- troll-army/375932/.

Sohn, D., Choi, S.M. (2014). Measuring expected interactivity: Scale development and validation. New Media \& Society, 16 (5), pp. 856-870.

Stryker, C. (2011). Epic Win for Anonymous: How 4Chan's Army Conquered the Web. New York: Overlook Duckworth.

TNS Latvia (2013/2014). Media research yearbook of TNS Latvia. Retrieved August 29, 2016 from http://www.tns.lv/wwwtnslv_resources/images/Mediju _petijumu_gadagramata/TNS_Latvia_mediju_petijumu_gadagramata_2013-2014.pdf. 
Walker, S. (2015, April 2). Salutin' Putin: Inside a Russian troll house. The Guardian. Retrieved July 17, 2016 from https://www.theguardian.com/world/2015/apr/02/putin-kremlin- inside-russiantroll-house.

Weichert, S. (2016, January-March). From swarm intelligence to swarm malice: An appeal. Social Media + Society, pp. 1-7.

\section{ANNEX 1.}

Table 3. Audience data of the Internet news sites (time period from August 1 to August 3, 2014; data only on PC users)

\begin{tabular}{|l|c|c|c|c|c|}
\cline { 2 - 6 } \multicolumn{1}{c|}{} & \multicolumn{1}{c|}{$\begin{array}{c}\text { Visitors } \\
\text { (real users) }\end{array}$} & $\begin{array}{c}\text { Avg. daily } \\
\text { visitors }\end{array}$ & $\begin{array}{c}\text { Avg. time } \\
\text { spent per } \\
\text { visitor } \\
\text { [hr:min:s] }\end{array}$ & $\begin{array}{c}\text { Avg. time } \\
\text { spent } \\
\text { per visit } \\
\text { [hr:min:s] }\end{array}$ & $\begin{array}{c}\text { Avg. visits } \\
\text { per visitor }\end{array}$ \\
\hline delfi.lv-DELFI- LAT & 253638 & 136950 & $00: 32: 08$ & $00: 09: 08$ & 3.37 \\
\hline delfi.lv-DELFI- RUS & 125711 & 70785 & $00: 48: 41$ & $00: 12: 49$ & 3.80 \\
\hline tvnet.lv-LV & 191003 & 172740 & $00: 40: 01$ & $00: 09: 38$ & 4.15 \\
\hline tvnet.lv-LV-Apollo.lv & 163726 & 107783 & $00: 21: 55$ & $00: 06: 45$ & 3.25 \\
\hline tvnet.lv-RUS & 101337 & 51054 & $00: 15: 10$ & $00: 06: 20$ & 2.40 \\
\hline
\end{tabular}

Source: audienceGemius. 